\title{
Life-History Observations, Environmental Associations, and Soil Preferences of the Piedmont Blue Burrower (Cambarus [Depressicambarus] harti) Hobbs
}

\author{
Brian S. Helms ${ }^{1, *}$, Chester Figiel ${ }^{2}$, John Rivera ${ }^{3}$, Jim Stoeckel ${ }^{4}$, \\ George Stanton ${ }^{3}$, and Troy A. Keller
}

\begin{abstract}
Cambarus (Depressicambarus) harti (Piedmont Blue Burrower) is a stateendangered primary burrowing crayfish found in highly organic soils associated with seepage areas only in Meriwether County, GA. As is the case with many native burrowing crayfishes, virtually nothing is known about the biology and ecology of this species. To help fill this gap, the current study provides information on population demographics, environmental correlates of activity, burrowing behavior, and habitat fidelity of $C$. harti. Field surveys from the type locality revealed that crayfish could be found throughout the year, with a near 3:1 ratio of female to male adults captured, an ovigerous female found in June, and the highest number of small juveniles found in August. Adults were not found together in burrows; however, juveniles were often found sharing the burrows of females. Burrowing activity was generally higher in the summer than winter, and also increased with receding groundwater levels. Based on observations and experiments with artificial burrowing chambers (ABCs), the burrows of $C$. harti followed a predictable form and were often capped with at least one chimney of seemingly deliberate construction. Total burrow area and mean chimney pellet diameter increased with crayfish size. It appeared that $C$. harti will burrow in other soils, but displays a strong affinity to its type-locality soils, particularly below groundwater level. Observations from a communal ABC revealed that adults use burrows to brood young and will share burrows with other adults for a period of time, possibly during burrow construction and/or times of disturbance, but eventually tend to segregate to solitary occupancy. Taken together, these data offer insight into the biology and ecology of this highly endemic and elusive animal that will be useful for management and conservation efforts and provide much-needed scientific information about burrowing crayfishes in general.
\end{abstract}

\section{Introduction}

The southeastern United States has one of the most diverse assemblages of crayfish species in the world, with approximately 275 crayfish taxa endemic to the region (Taylor et al. 2007). Although generally associated with open water, nearly all crayfish can burrow to some degree (Berrill and Chenoweth 1982), and many spend a majority of their lives in a semi-terrestrial existence. Often categorized as primary, secondary, or tertiary burrowers (Hobbs 1981), the excavations

\footnotetext{
${ }^{1}$ Department of Biological Sciences, Auburn University, Auburn, AL 36849. ${ }^{2}$ Warm Springs Fish Technology Center, US Fish and Wildlife Service, Warm Springs, GA 31830. ${ }^{3}$ Department of Biology, Columbus State University, Columbus, GA 31907. ${ }^{4}$ Department of Fisheries and Allied Aquacultures, Auburn University, Auburn, AL 36849. ${ }^{5}$ Department of Earth and Space Sciences, Environmental Science Program, Columbus State University, Columbus, GA31907. . Corresponding author-HELMSBS@auburn.edu.
} 
of crayfish can range from relatively simple blind tubes to extensive subterranean labyrinths (Grow 1981, Hasiotis 1993, Welch et al. 2008). These actions can mix and disturb local soils, increasing soil habitat complexity (Welch et al 2008) and respiration (Richardson 1983, Stone 1993), and serve as refugia for other organisms (Loughman 2010, Pintor and Soluk 2006). Although there have been many studies documenting life histories and/or distributions of individual species (e.g., Johnston and Figiel 1997), compared to their stream-dwelling counterparts, generally little is known about the biology and ecology of burrowing crayfish (Guiaso 2009, Skelton 2010, Taylor et al. 2007). Further, about a quarter of the crayfish species considered threatened or endangered in North America are primary burrowers (Taylor et al. 2007). Subterranean behavior combined with rarity presents unique challenges in the study of these organisms. However, knowledge of basic biology, ecology, and behavior of crayfishes is central for population management and conservation efforts. The current study implements traditional and novel approaches to investigate the life history and behavior of a rare, narrowly distributed burrowing species in the Piedmont of Georgia. Cambarus harti Hobbs (Piedmont Blue Burrower) is an obligate burrowing species (i.e., primarily confined to subterranean burrows) only known from a few locations in the Flint and Chattahoochee river drainage basins on the western Piedmont Plateau within Meriwether County, GA. It is listed as endangered in the state of Georgia and by the International Union for the Conservation of Nature (IUCN). Currently it has no US federal protection. Except for general habitat associations, very little is known about the life history of this species (Hobbs 1981). This crayfish reaches a total length of approximately $70 \mathrm{~mm}$ and has dorsum and appendages colored deep cobalt blue, and its ventral side is a pinkish-cream with tan splotches. It is distinctively broader in the cephalothorax than the abdomen, with small narrow eyes, a nearly obliterated areola, and moderately robust chelae (Hobbs 1981). Cambarus harti has been found mainly in complex tunnels near springs and seeps in wooded areas with sandy, humus soils and high water tables (Hobbs 1981, Skelton et al. 2002).

Concern is growing about the future status of crayfishes in Georgia, particularly in the fast-growing 28-county Atlanta metropolitan area, to which Meriwether County belongs (Metro Atlanta Chamber of Commerce 2006, Skelton 2010). Groundwater fluctuations and other conditions associated with climate change and local anthropogenic disturbance, particularly habitat destruction or degradation, are direct threats to $C$. harti populations. For example, the site where Hart and Hart (1974) captured individuals has had vegetation removed via logging operations, and the species may no longer inhabit that location. Additionally, as this species is an obligate burrower it may be susceptible to habitat changes related to groundwater that are not apparent at the surface. Thus, the objective of this study was to obtain information on population demographics, environmental correlates to activity, burrowing behavior, and habitat fidelity of C. harti that could improve management and conservation efforts and provide much-needed scientific information about burrowing crayfishes in general. 


\section{Methods}

\section{Field site}

We conducted field investigations and collected crayfish from the type locality (Hobbs 1981), a wooded seep at an elevation of $265 \mathrm{~m}$ along the Pine Mountain Ridge in Meriwether County, GA, adjacent to the US Fish and Wildlife Service Warm Springs National Fish Hatchery. Plant associates included Smilax spp. (greenbriars) and Arundinaria spp. (canes) as well as many evergreen or semi-evergreen trees and shrubs, such as Magnolia virginiana L. (Sweet Bay Magnolia), with an overstory comprised of Quercus spp. (oaks), Acer spp. (maples), Liriodendron tulipifera L. (Tulip Poplar) and Magnolia grandiflora L. (Southern Magnolia). The saturated soil of this seep is classified as Habersham gravelly loamy sand and is highly organic and acidic with a pH of 4.6 (Auburn University Soil Testing Laboratory, Auburn, AL).

\section{Field surveys, habitat, and burrowing activity}

In order to quantify seasonal activity patterns and population demographics, surveys were conducted in two $30-\mathrm{m}^{2}$ plots approximately $100 \mathrm{~m}$ apart. Crayfish collection efforts were conducted 5 times per month over a 3.5-year period from October 2007 to April 2011 (except January, February, and June, 2009 due to lack of available personnel). Thus, total collection efforts were 20 visits for March and October-December, 15 visits for January, February, and April-September, and 10 visits for June. A site visit was considered a unit of effort for calculating catch per unit effort. Due to the initial low success rate of passive trapping, active burrows (as identified by fresh chimneys or recently exhumed soil near burrow entrances) were excavated by hand. Only burrows that showed recent activity were excavated, and each plot was thoroughly searched at each collection event by 1-2 individuals during daylight hours for approximately 1 hour. Thus, a similar, but not identical, effort was maintained for each collection. Gender, carapace length (CL) and width, palm length (lateral margin), and width of the right chela were measured to the nearest $0.1 \mathrm{~mm}$ with dial calipers. Based on previous studies (e.g., DiStefano et al. 1991) as well as histograms of captured specimens, juveniles were determined to be crayfish with a carapace length smaller than $20 \mathrm{~mm}$. All crayfish were released into burrows near where they were captured except for six crayfish that were used for laboratory experiments and subsequent observation. Although crayfish were not marked to account for recaptures, a given burrow was only excavated once, and burrow re-builds were left undisturbed. Additionally, the nearby spring draining the seep was searched occasionally throughout the study using dip nets and baited minnow traps, but no crayfish were collected in these efforts. To monitor groundwater temperature and level, a pressure transducer levelogger (SOLINST ${ }^{\circledR}$ Levelogger Gold, Solinst Canada LTD) encased in a PVC well was installed onsite at a depth of $70 \mathrm{~cm}$ in January 2009 and recorded data every 15 minutes for the duration of field collections. Level data 
were corrected for fluctuations in local atmospheric barometric pressure using data from a gage located at Fort Benning, GA $(<80 \mathrm{~km}$ distance $)$. Conductivity, $\mathrm{pH}$, and dissolved oxygen of burrow water were also measured (YSI ${ }^{\circledR} 556$ MPS, YSI Inc., OH) from each burrow whenever collections occurred.

To determine if environmental cues influenced crayfish activity, we monitored burrows every other day for six weeks in summer (15 visits from 28 May-8 July 2010) and 13 weeks in the winter/spring (24 visits from 9 January-30 March 2011) in two $\approx 8-\mathrm{m}^{2}$ sub-plots of densely populated habitats at the Warm Springs type locality. All burrows within the sub-plots were marked with a labeled flag, and observations of surface activity were recorded upon each visit. Except for monitoring activity, burrows within sub-plots were left undisturbed (i.e., no burrow excavation occurred). During each visit, we recorded the presence of chimneys, piles of mud pellets, covered burrows, new burrows, and excavated sands. Burrows with some degree of surface disturbance were scored as active. We tested for differences in the proportion of active burrows between seasons (both sites combined) with an independent samples $t$-test that did not assume equality of variances. We analyzed the correlation between the proportion of active burrows on a given sampling date and mean daily groundwater temperature, mean daily air temperature, and mean groundwater level (since last sample date). This window of time was used to capture the time lag associated with rain events and changes in groundwater flow. Data on the proportion of active burrows were arcsine square root transformed before all analyses (Sokal and Rohlf 1995).

\section{Soil fidelity and burrow characterization}

We conducted a burrowing experiment to examine fidelity of $C$. harti to type-locality soil and to gain insight into burrowing behaviors. A soil preference test was conducted in the laboratory using type-locality soil from Warm Springs and a lab-mixed clayey loam, which was the preferred soil of the closely related $C$. striatus Hay (Ambiguous Crayfish) in a previous study (Stoeckel et al. 2011). We used acrylic artificial burrowing chambers (ABCs) that were $30 \mathrm{~cm} \mathrm{H} \mathrm{x} 46 \mathrm{~cm} \mathrm{~L} \mathrm{x} 5 \mathrm{~cm} \mathrm{~W}$ for the preference trial (Stoeckel et al. 2011). Chambers were filled with type-locality loam in one half and with clayey loam test soil in the other half. The halves were separated by a thin plastic partition that was removed after the soils were added (Fig 1A). Once filled, the partition was removed, and simulated groundwater was raised to the top of the chambers for $24 \mathrm{hrs}$ to saturate soils, and then dropped to $15 \mathrm{~cm}$ below the surface on day 2 for the remainder of the experiment to promote active burrowing (Stoeckel et al. 2011). This depth promotes expeditious burrowing and minimizes burrow collapse in the ABCs. On day 3, a single female $C$. harti was placed in each $\mathrm{ABC}$ and allowed to burrow for five days. Chimney dimensions (height, width, depth) were measured daily with calipers, while burrow shape and vertical cross-sectional area were determined from digitized daily tracings using Image $J^{\circledR}$ software. Due to their protected status, only five individuals were used in this experiment. All crayfish were 
adult females (carapace length $24-32 \mathrm{~mm}$ ) collected in early summer 2010 . We used linear regression analysis to relate crayfish size to burrow measurements and paired $t$-tests to determine if measurements of burrow area differed between the two soil types at peak burrow area.

\section{Burrow sharing, reproduction, and brooding in the lab}

To document communal burrowing, reproduction, and brooding behavior in the lab, we linked six $\mathrm{ABCs}$ to a common-surface arena so that crayfish could move freely among chambers (Fig. 1B). Groundwater level was maintained at $15 \mathrm{~cm}$ below the sediment surface and at $\approx 21{ }^{\circ} \mathrm{C}$ in the burrowing chambers. A separate, surface water stream ran through the center of the surface chamber.

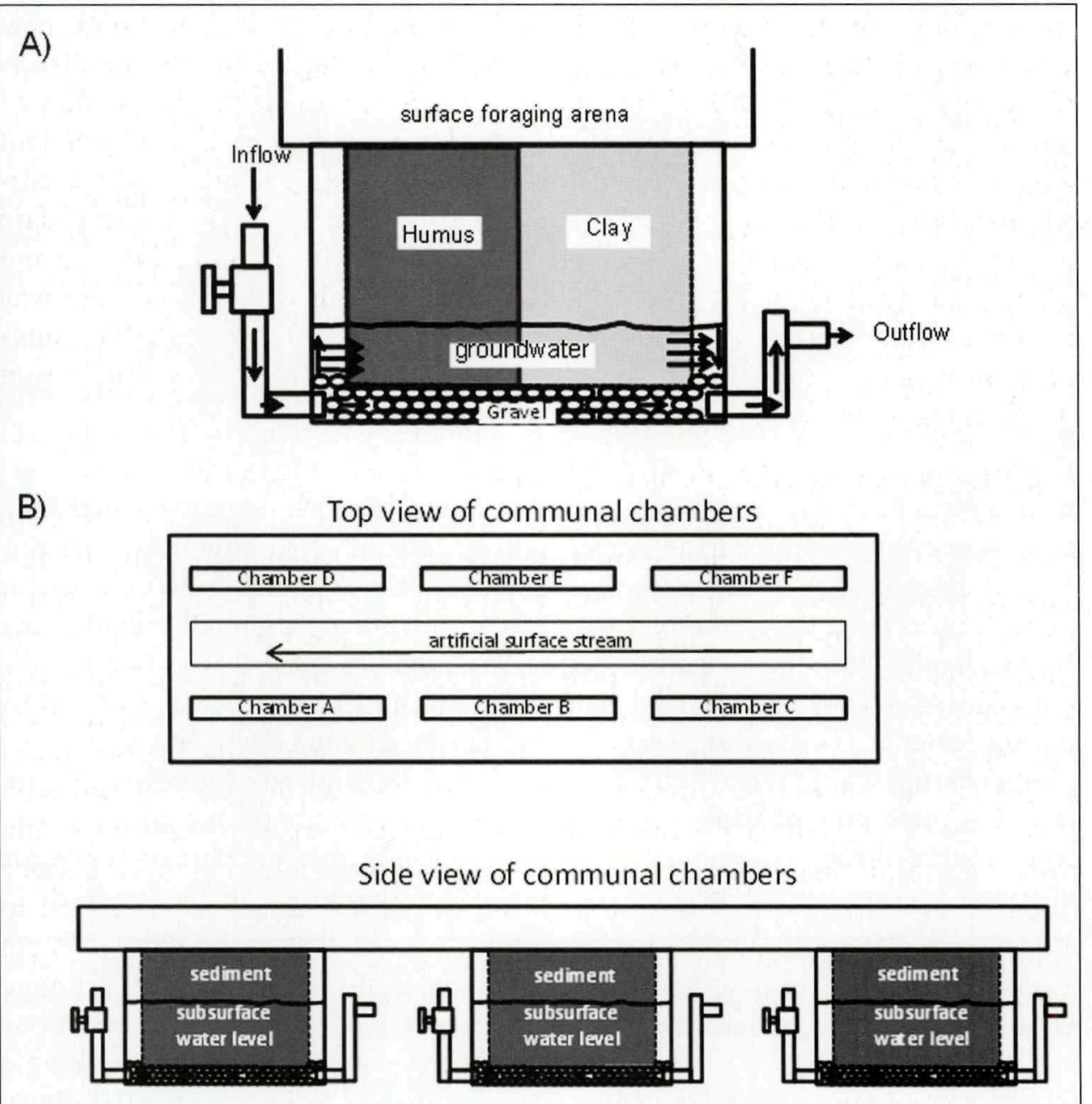

Figure 1 A) Schematic diagram of artificial burrowing chamber filled with humus (type-locality) and clay (lab-mixed) soils for soil fidelity test. B) Schematic diagram of communal burrowing chambers. Six artificial burrowing chambers were connected at the surface by a common surface chamber with a surface water stream through the center of the surface chamber, arrow denotes flow. 
Each chamber was filled, and the communal surface was covered $(\approx 2 \mathrm{~cm}$ depth) with type-locality soils with a constant light cycle held at 14:10 light:dark. One male and five females (used in previous trials) were placed haphazardly in the surface arena in February 2011 and allowed to burrow freely among the six chambers. A PIT tag was attached to the cephalothorax of each crayfish with underwater epoxy prior to introduction into the arena and the location of each crayfish recorded daily to weekly via a PIT tag antennae swept along the burrowing chamber walls. Crayfish were fed shrimp pellets ad libitum via the burrow entrance throughout the course of the observation. Crayfish were periodically videotaped using a SONY handycam (HDR-XR200V) to directly record burrowing behavior, brooding behavior, and offspring activities.

\section{Results}

\section{Field surveys}

A total of 54 unique $C$. harti individuals were collected over the course of the study. All C. harti were collected from burrows, with the exception of one female that was collected by hand during a nighttime rain event near the seepage spring (26 September 2010). Cambarus latimanus (LeConte) (Variable Crayfish) was also found in the seepage spring throughout the collection period; however, no other crayfish species were found burrowing in the study area.

Of the 54 crayfish captured, adults were at a near $3: 1$ sex ratio, with $37 \%$ female, $13 \%$ male, and $50 \%$ juveniles. Crayfish carapace color varied from dark cobalt blue to a rusty pink/violet as similarly described by Hobbs (1981). Captured adult females were slightly larger than males on average for all body measurements (Table 1). Adults were not found together within a single burrow; however, several burrows occupied by females also contained apparent free-living juveniles of the same apparent size-class. Crayfish were collected in most months (Fig. 2). Reproductively active individuals captured included two Form I males and one ovigerous female collected in June 2010. Twenty-four crayfish (44.4\%) were collected during the spring (March-May), 19 (35.2\%) during summer (June-Aug), seven (13\%) during autumn (Sep-Nov), and four (7.4\%) during winter (Dec-Feb). The month with the highest capture was August $(n=15)$, with nine of these being small juveniles apparently recently released from adult females. No crayfish were collected in January, February, or April, although surveys were conducted during those time periods and active burrows

Table 1. Sample sizes $(n)$ and means (standard deviations) of carapace length $(\mathrm{CL})$, carapace width $(\mathrm{CW})$, palm length, lateral margin (PL), palm width (PW), and weight (Wt) of Cambarus harti from Warm Springs, GA. Lengths and widths are in $\mathrm{mm}$, weight in grams.

\begin{tabular}{lccc} 
Measurement & Female $(n=20)$ & Male $(n=7)$ & Juvenile $(n=27)$ \\
\hline CL & $27.2(4.8)$ & $23.6(4.7)$ & $10.3(4.2)$ \\
CW & $12.9(2.5)$ & $10.1(1.4)$ & $5.2(1.4)$ \\
PL & $15.8(3.5)$ & $12.7(3.8)$ & $7.2(2.1)$ \\
PW & $7.7(2.1)$ & $6.8(2.6)$ & $4.1(0.3)$ \\
Wt & $3.8(2.8)$ & $3.0(1.2)$ & $0.3(0.1)$ \\
\hline
\end{tabular}


were observed. Catch per unit effort was also highest in August, March, and May and lowest in January, February, and April (Fig. 2). The average size of captured juvenile crayfish was smallest in August and December and generally increased through the spring and summer (Fig. 3).

Physicochemical conditions in and around the burrows varied throughout the study period (Table 2). Measured groundwater level fluctuated a total of $10.4 \mathrm{~cm}$ over the period of record. At the well (which was not at the exact elevation of every burrow), water levels were below the surface, ultimately reaching $-14.2 \mathrm{~cm}$ in summer 2010, with an average level of $-7.9 \mathrm{~cm}$, reaching a minimum depth of $-3.8 \mathrm{~cm}$ in spring 2010 (Table 2, Fig. 4). Burrow water chemistry was generally stable, with low $\mathrm{pH}(4.6-5.2)$, conductivity (17-25 $\mu \mathrm{S})$, and dissolved oxygen levels (1.3-2.4 mg/L) (Table 2). Burrow water temperature followed similar trends as air temperature, but showed less variation (Table 2, Fig. 4).

\section{Burrow activity}

Crayfish were active throughout early spring and summer as evidenced by the capture of individuals from active burrows (Fig. 2). New burrowing activity occurred during both the May-July (2010) and January-March (2011) periods of intense monitoring. We monitored 106 burrows and found higher activity in the summer than in the winter period ( $t$-value $=3.9, P<0.0001$; Fig. 5). There

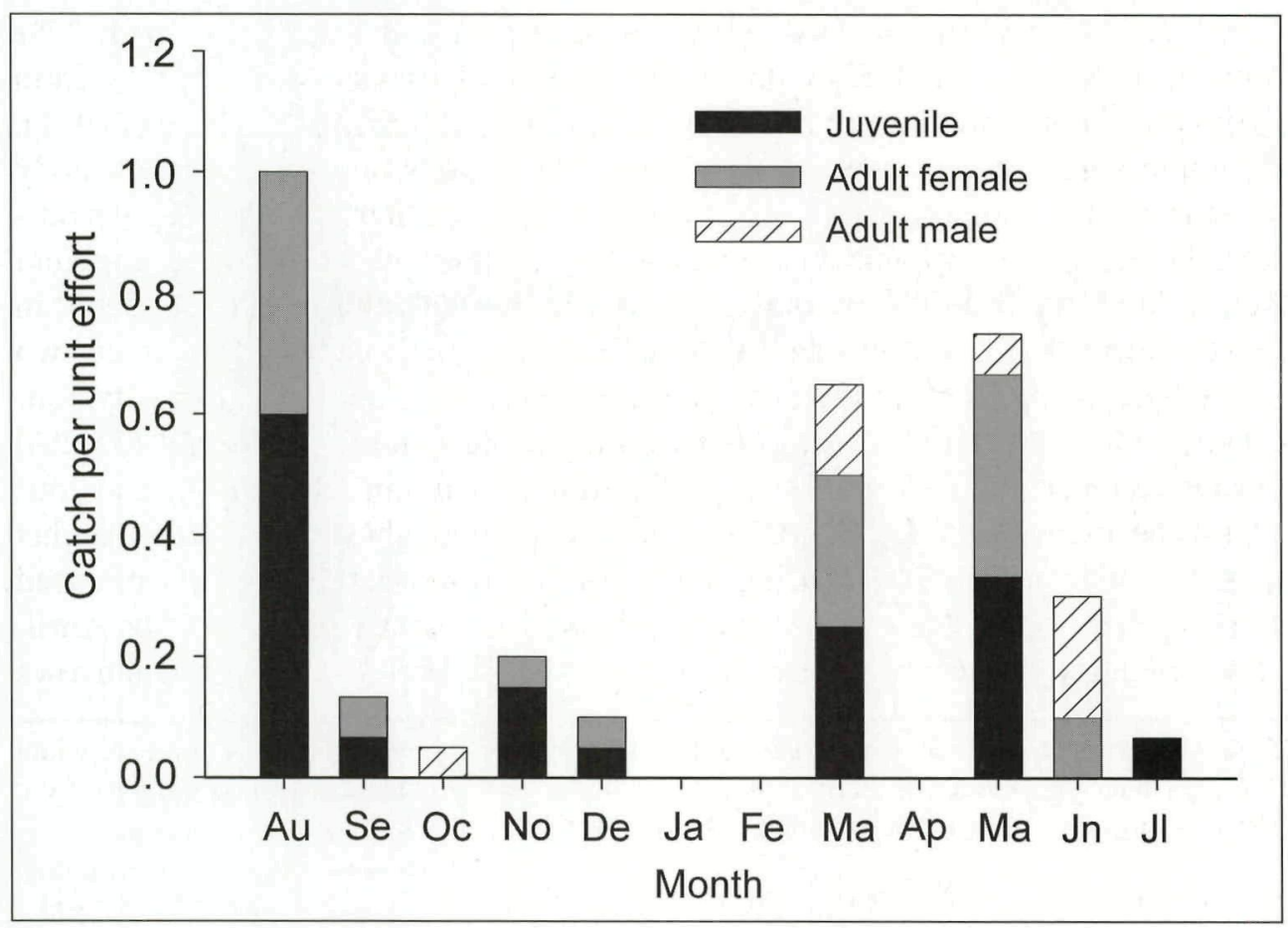

Figure 2. Seasonality of captured individuals of $C$. harti over the course of the study. Juvenile crayfish were individuals with $<20 \mathrm{~mm}$ carapace length. Catch per unit effort is the number collected per collection event (20 for Jan-Mar, Oct-Dec; 15 for Apr-Sep.). Months are arranged beginning with August, as the highest abundance of small juveniles were recorded then. 
existed no significant correlation between the proportion of active burrows and the air temperature $(r=-0.26, P=0.2)$ or water temperature $(r=-0.39, P=$ $0.065)$. However, surface burrow activity increased as mean groundwater level dropped $(r=0.469, P=0.024)$. Fewer burrows showed activity when ground water levels were close $(-8 \mathrm{~cm})$ to the surface (Fig. 6).

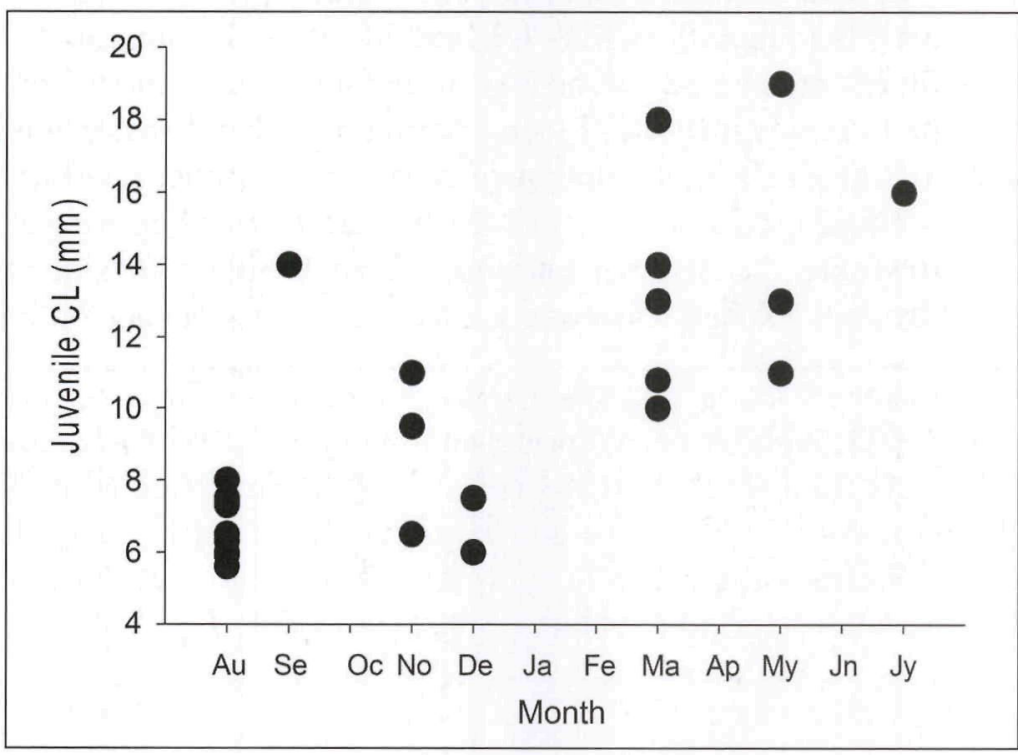

Figure 3. Juvenile crayfish carapace length by month of capture, beginning in August. Collections were made from $2007-2010$, with multiple years are aggregated.

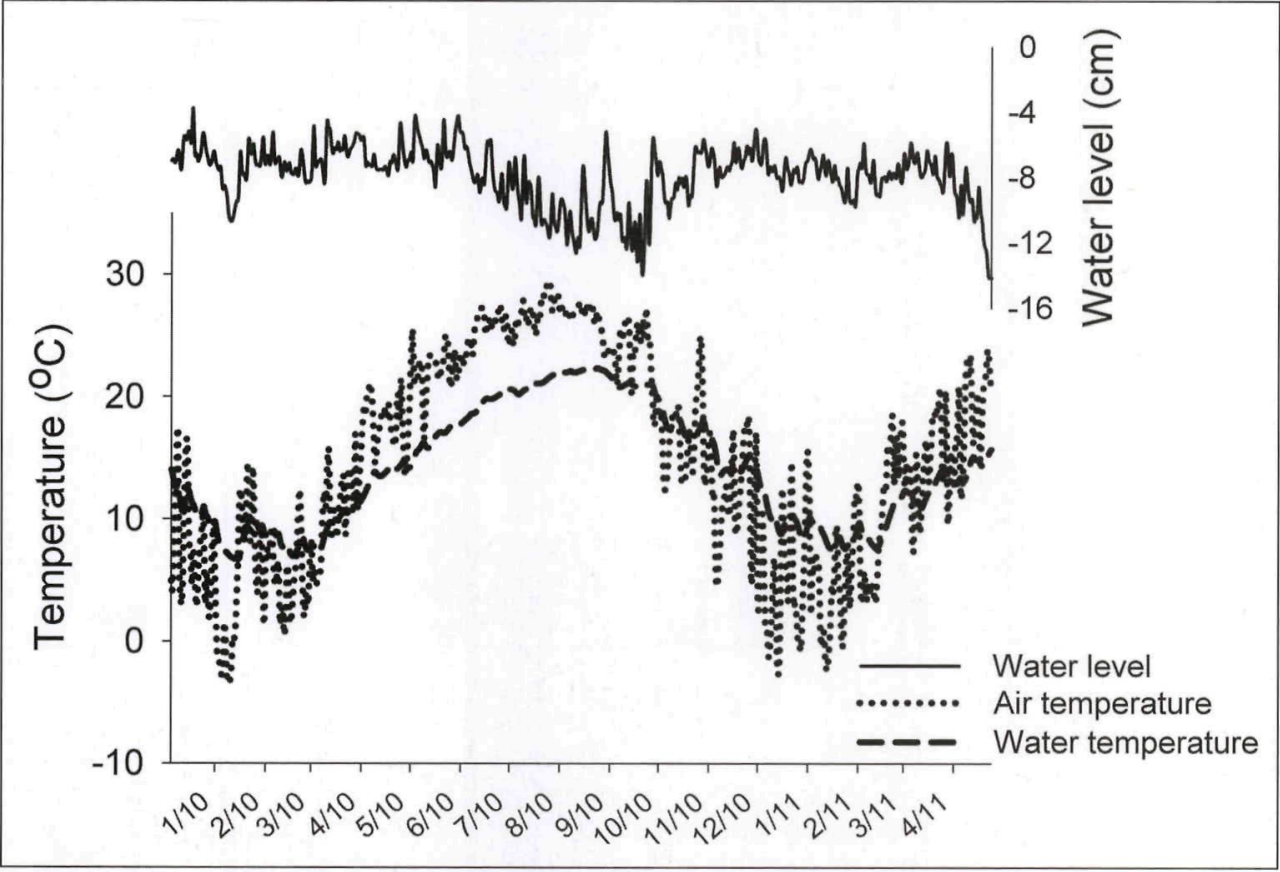

Figure 4. Groundwater levels, groundwater temperature, and air temperature at the study site for the period of record. For water level, $0=$ ground; thus, negative values are subsurface, and positive values are standing water. 


\section{Burrowing experiments}

All five $C$. harti used for the substrate preference experiment readily burrowed in the $\mathrm{ABCs}$ within 24 hours of introduction. Most burrow water conditions in the $\mathrm{ABCs}$ were similar to conditions observed in the field, although DO was higher than field observations. With the exception of one burrow initiated near the vertical soil edge, resulting in a fresh influx of sump water $(\mathrm{pH}=6.4, \mathrm{DO}=$ $6.0 \mathrm{mg} / \mathrm{L}$ ), burrow water $\mathrm{pH}$ ranged from 4.4-4.9, and DO ranged from 2.3-4.1 $\mathrm{mg} / \mathrm{L}$. Burrow development proceeded by construction of an initial tunnel, generally near the soil-type interface followed by excavation of a chamber near the water table (Fig. 7a) and often the construction of an alternate tunnel and burrow expansion by day 2 (Fig. 7b). Days 3 and 4 were characterized by further expansion of the burrow (Fig. 7c, 7d) with minimal further development and some burrow collapse by day 5 . When not actively excavating, crayfish generally

Table 2. General physicochemical conditions of Cambarus harti burrows at Warm Springs, GA. Air temperature is surface-level air temperature. Burrow temperature, water level, conductivity, $\mathrm{pH}$, and DO refer to water in the burrow. Water level is $\mathrm{cm}$ relative to ground surface. Diameter is the burrow diameter at the surface. Values are based on weekly means.

\begin{tabular}{lrrr} 
& Average \pm SD & Max & Min \\
\hline Air temperature $\left({ }^{\circ} \mathrm{C}\right)$ & $14.9 \pm 8.7$ & 29.5 & -3.4 \\
Burrow temperature $\left({ }^{\circ} \mathrm{C}\right)$ & $14.1 \pm 4.8$ & 22.3 & 6.7 \\
Water level $(\mathrm{cm})$ & $-7.9 \pm 1.8$ & -3.8 & -14.2 \\
Conductivity $(\mu \mathrm{S})$ & $21.0 \pm 5.7$ & 25.0 & 17.0 \\
$\mathrm{pH}$ & $4.9 \pm 0.5$ & 5.2 & 4.6 \\
DO $(\mathrm{mg} / \mathrm{L})$ & $1.8 \pm 0.8$ & 2.4 & 1.3 \\
Diameter $(\mathrm{mm})$ & $23.9 \pm 7.9$ & 45.0 & 5.0 \\
\hline
\end{tabular}

Figure 5. Comparison of crayfish surface burrowing activity across two sampling periods. Plots indicate mean proportion (+1 SD) of burrows found to have new activity during surveys. Plotted burrow proportions are acrsine $\sqrt{x}$ transformed values.

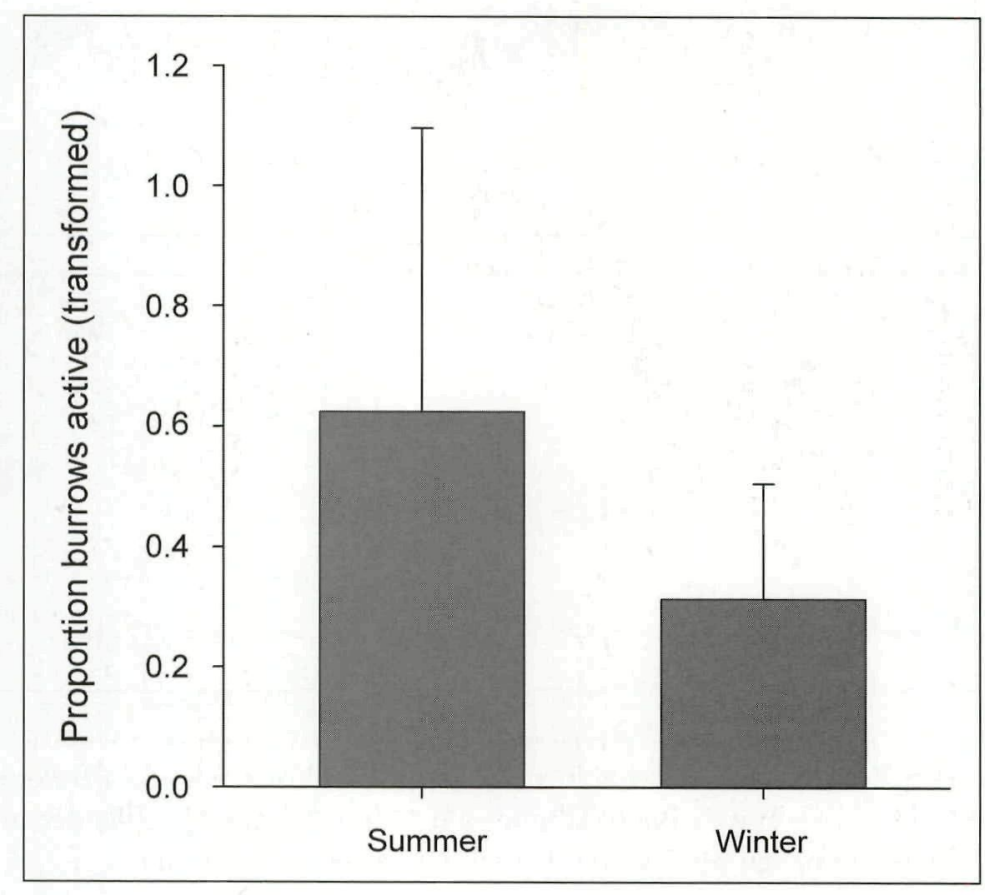


were observed resting just above the water interface in the burrow or in the burrow water itself. Total burrow area after $4 \mathrm{~d}$, which represented the day of peak burrow area, was significantly related to crayfish CL $\left(R^{2}=0.94, P=0.006\right.$;

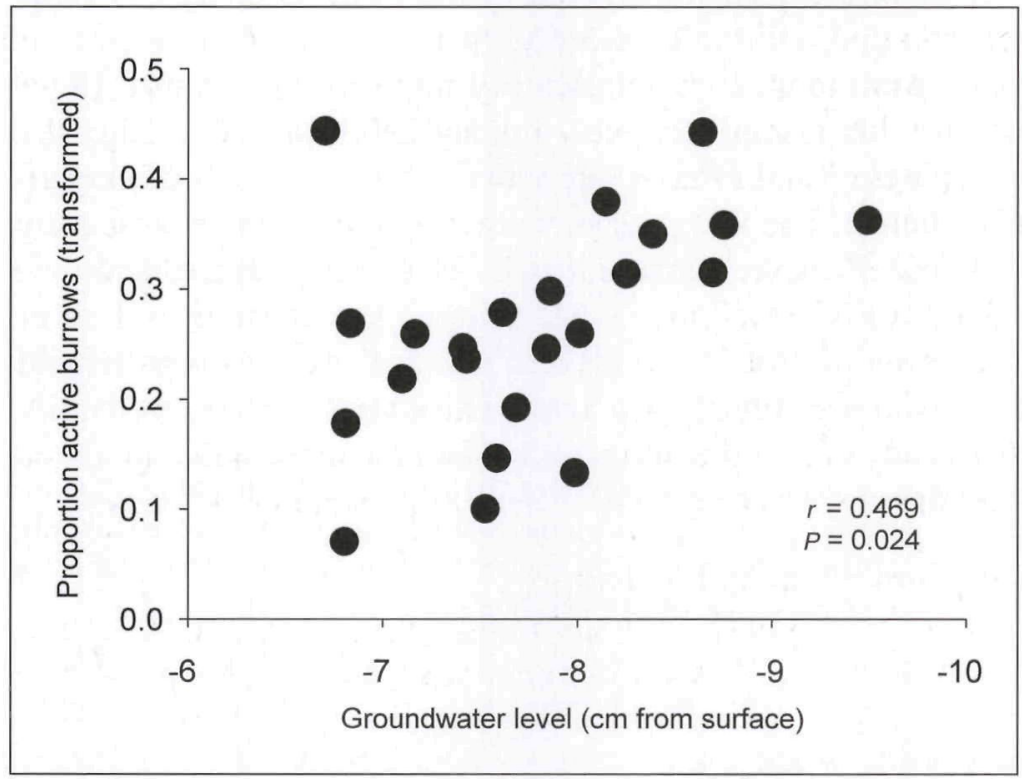

Figure 6. Relationship between ground water level (cm from surface) and proportion of active burrows. Plotted burrow proportions are acrsine $\sqrt{\mathrm{x}}$ transformed values.

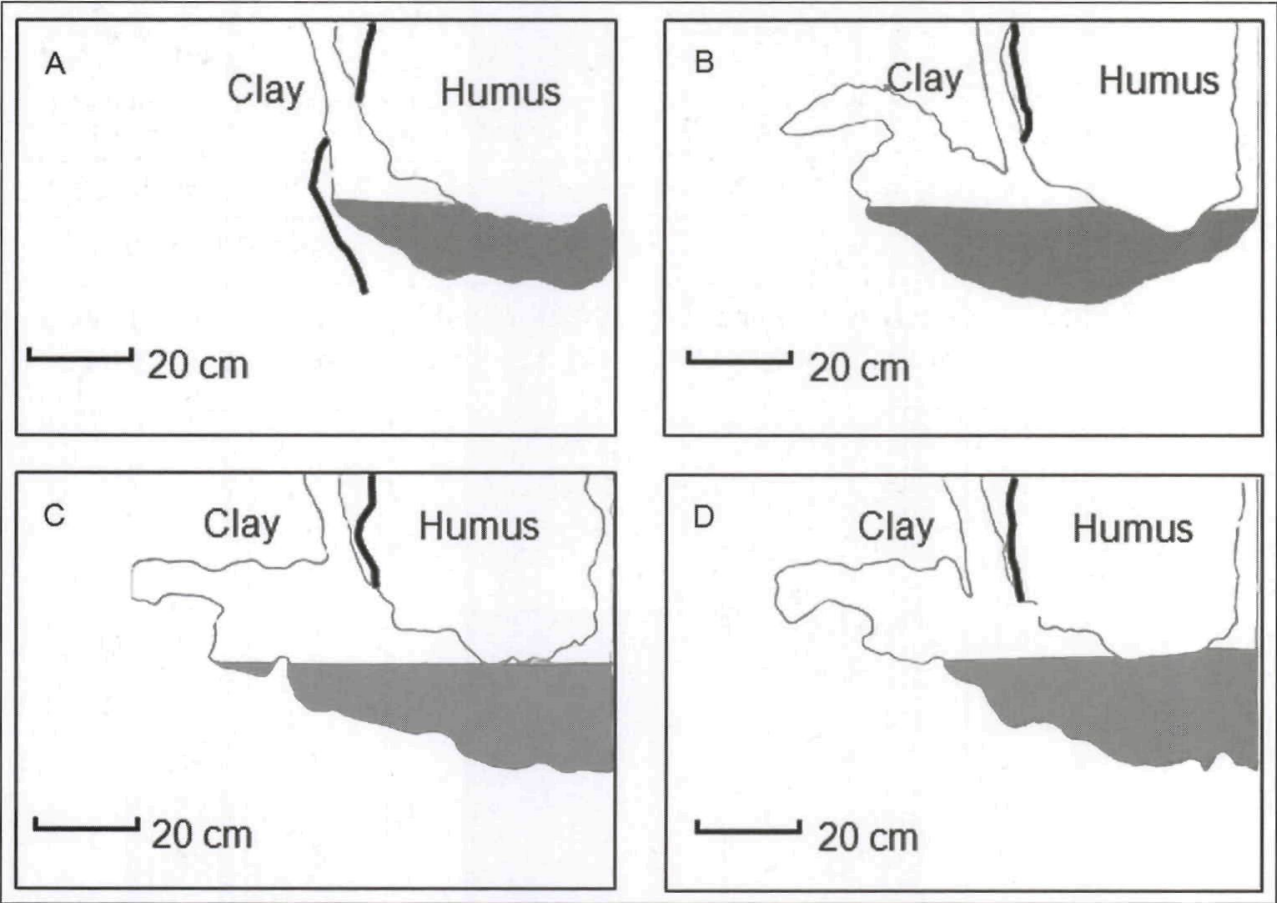

Figure 7. Four-day evolution of $C$. harti burrow in artificial burrowing chamber. Bold vertical line (straight prior to crayfish introduction) denotes the edge of the soil treatments $($ Clay $=$ clayey loam, Humus $=$ type locality soil $)$ and shaded area is the underwater component of the burrow. Panels A, B, C, and D refer to days 1, 2, 3, and 4, respectively. 
Fig. 8a). By day 4, crayfish had excavated more in type-locality $\left(129.1 \mathrm{~cm}^{2} \pm 38.7\right.$ $\mathrm{SD})$ than test soil $\left(71.2 \mathrm{~cm}^{2} \pm 50.5 \mathrm{SD}\right)$ in terms of total burrow area $(t$-value $=$ $4.67, P=0.009$; Fig. 9a). Underwater burrow area showed a similar trend $(t$-value $=4.38, P=0.012)$, with more excavation in the type-locality locality $\left(76.1 \mathrm{~cm}^{2}\right.$ $\pm 43.4 \mathrm{SD})$ than test soil $\left(8.6 \mathrm{~cm}^{2} \pm 10.3 \mathrm{SD}\right.$; Fig. $\left.9 \mathrm{~b}\right)$.

All initial burrows were topped with a chimney made of well-formed round pellets. There was no relationship between chimney height and CL (Fig. 8b). Based on video recordings of nighttime activity, the material for chimney pellets came from within the burrow and was placed in tapering mounds similar to what was observed at the field sites (see Supplemental Video File 1, available online at http://www.eaglehill.us/SENAonline/suppl-files/s12-1-1059-Helms-s1, and, for BioOne subscribers, at http://dx.doi.org/10.1656/S1059.s1). Mean pellet size for each chimney was significantly related to crayfish CL $\left(R^{2}=0.91, P=0.011\right.$; Fig. 8c). Generally the opening of the initial tunnel had the most elaborate chimney, with subsequent openings having no or considerably smaller chimneys.

\section{Burrow sharing, reproduction, and brooding}

All six crayfish burrowed within 24 hours of being placed at the surface of the communal system, resulting in two communal burrows with three crayfish

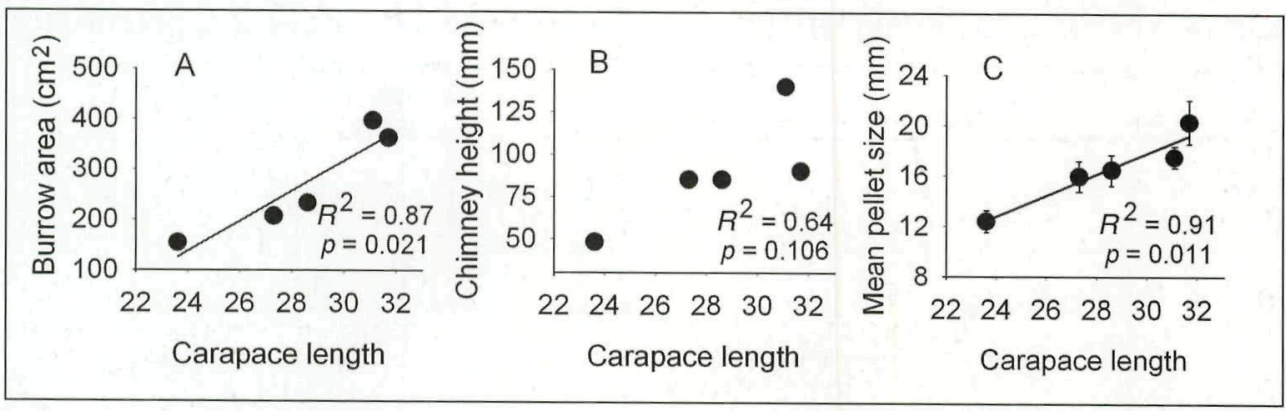

Figure 8. Relationships between carapace length $(\mathrm{mm})$ and burrow area, chimney height, and mean pellet size in the soil preference laboratory experiment. Error bars in $\mathrm{C}$ are $\pm 1 \mathrm{SD}$.

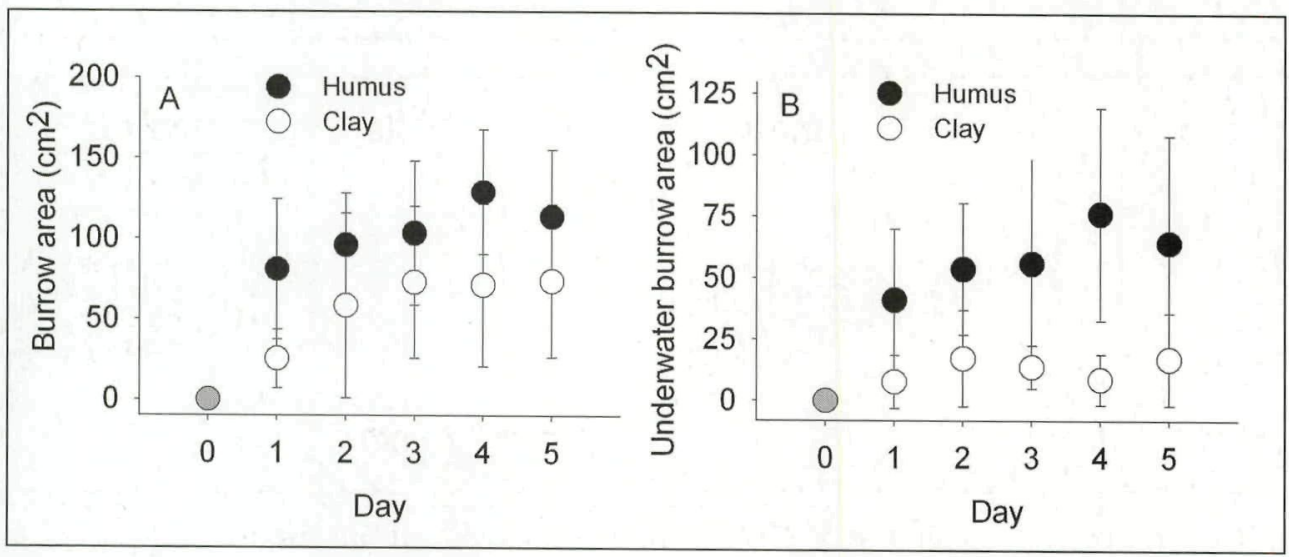

Figure 9. Total (A) and underwater (B) burrow area $\left(\mathrm{cm}^{2}\right)$ for the clay and humus treatments over the 5 -day trial. Points are daily means $( \pm 1 \mathrm{SD})$ calculated from the 5 replicate $\mathrm{ABCs}$. The gray point represents the beginning of the trial. 
in each (Fig. 10: chambers A and D; see Supplemental Video File 2, available online at http://www.eaglehill.us/SENAonline/suppl-files/s12-1-1059-Helmss2, and, for BioOne subscribers, at http://dx.doi.org/10.1656/S1059.s2). Four females, two from A and two from D, had migrated to chamber E by day 6 (Fig. 10), leaving the solitary male in chamber D and a solitary female in chamber A. The solitary male was found dead on day 6 . Two subsequent changes in burrow occupancy (days 9 and 11) occurred after communal burrows were disturbed to retrieve seemingly dead crayfish, although no additional mortality had occurred at this point. After day 11, all crayfish remained in their respective burrows. One female (communal burrow, chamber F) was found dead on day 13 , and another (solitary burrow, chamber A) was found dead on day 44 . The remaining crayfish $(n=3)$ remained in their respective burrows for over 3 months (99 days). The maximum number of crayfish observed within a shared burrow was four (chamber E). Solitary burrows (chambers A and D) occurred only after all but one crayfish abandoned the burrow. Two burrowing chambers (chambers $\mathrm{B}$ and $\mathrm{C}$ ) were never colonized (Fig. 10).

On day 78 (April 27, 2011), an ovigerous female was observed in a solitary burrow (chamber E) with approximately 12 light orange eggs under her abdomen. The timing of this observation differed with the one ovigerous female captured in the wild ( 3 June 2010). The female in the laboratory was potentially

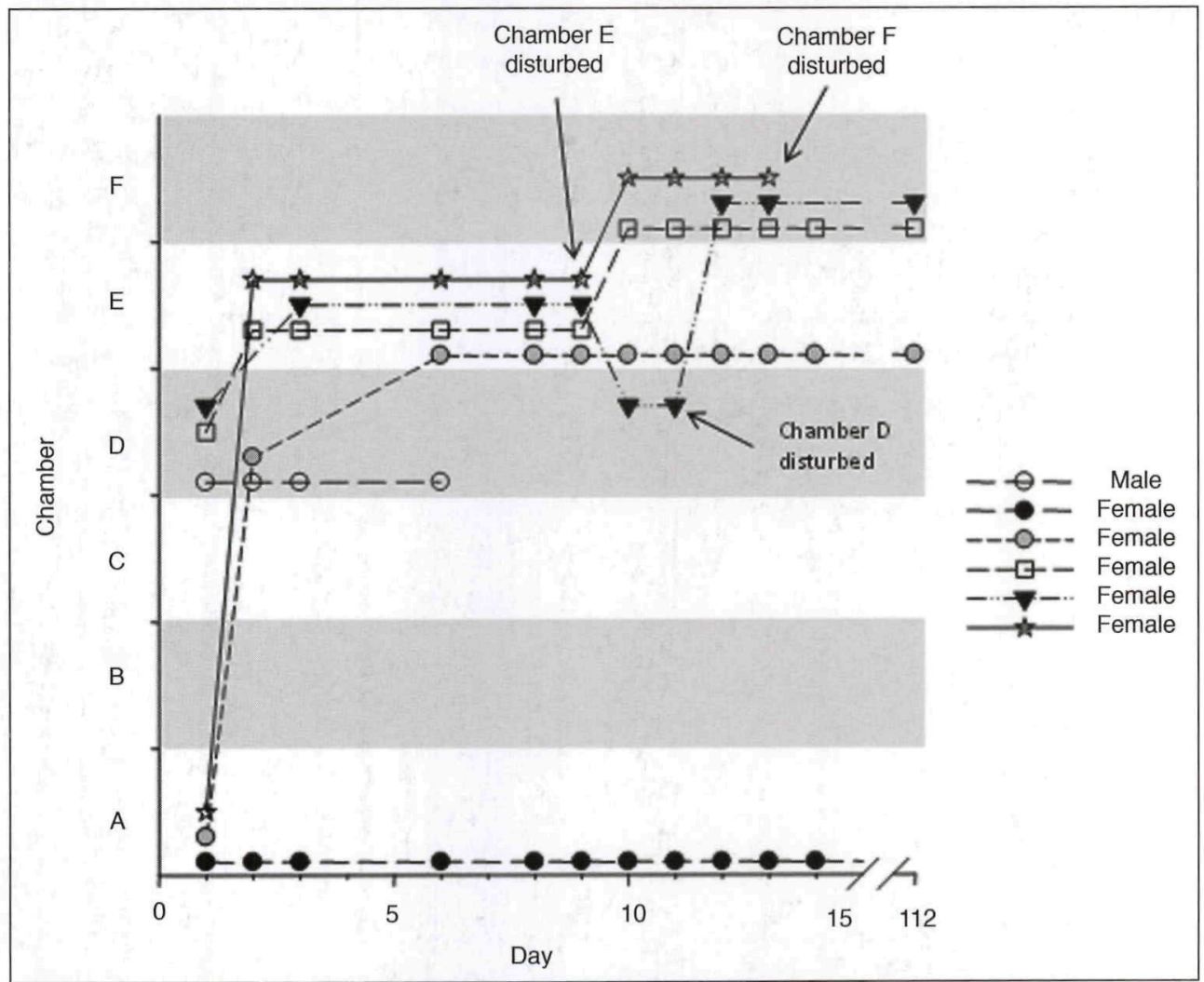

Figure 10. Chamber colonization by 5 females and one male $C$. harti. Arrows designate times when burrows were disturbed. Chambers $\mathrm{C}$ and $\mathrm{B}$ were never colonized. 
fertilized by the lone male before his death, as she had spent one day in the male burrow (chamber D, day 2, 10 February 2011) prior to moving to chamber $\mathrm{E}$ and had been held in the lab since June 13 ( 8 months prior to these observations) under solitary conditions, or conversely, she stored sperm for over 8 months from an encounter in the wild. Egg coloration remained constant (orange) through day 101 (20 May 2011). On day 106 (25 May 2011), we observed the female actively fanning her pleopods, which appeared covered in a mass of fungal filaments and sediment. By day 111 (30 May 2011), newly hatched juveniles were visible on one side of her abdomen, while the other side appeared to be covered by a mass of fungi and sediment. Detached juveniles were observed in the burrow on day 112. On day 114 (2 June 2011), the burrow ceiling collapsed on the female and juveniles, but by day 115, two juveniles were cooperatively burrowing (see Supplemental Video File 3, available online at http://www.eaglehill.us/SENAonline/suppl-files/s12-1-1059-Helms-s3, and, for BioOne subscribers, at http://dx.doi.org/10.1656/S1059.s3), and another juvenile was observed actively foraging on soil invertebrates. The adult female re-excavated her burrow, incorporating the smaller burrows of the juveniles. By day 134 (20 June 2011), juveniles had reached a size of approximately 13 mm total length. As of day 193 (20 Aug 2011), at least 4 juveniles ranging in size from $16-25 \mathrm{~mm}$ remained in the burrow, with little to no sign of aggression between the adult and juveniles (see Supplemental Video File 4, available online at http://www.eaglehill.us/SENAonline/suppl-files/ss 12-1-1059-Helmss4, and, for BioOne subscribers, at http://dx.doi.org/10.1656/S1059.s4). Thus, time from mating to spawning was approximately 11 weeks, with eggs hatching within $\approx 4$ weeks, and juveniles detaching within one week of hatching. Juveniles actively burrowed and foraged within one week of detachment and remained in the maternal burrow for $\geq 11$ weeks following detachment.

\section{Discussion}

Burrowing crayfishes are notoriously difficult to study as a result of their elusive behavior, often localized distributions, and difficulty in collecting. Consequently, there is very little life-history and ecological information associated with burrowers as compared to their stream-dwelling counterparts. Exemplified by its capture difficulty and very narrow distribution (Meriwether County, GA), C. harti is no exception to this general trend. As such, prior to this study, very little information was available regarding this species (see Cooper and Skelton 2003, Hobbs 1981, Skelton et al. 2002).

The current study on the natural history of a $C$. harti population near Warm Springs, GA suggests that these crayfish reside in single-species colonies with a skewed adult sex ratio ( $3 \mathrm{~F}: 1 \mathrm{M}$ ). Female-biased sex ratios are common in some arthropods with small reproductive populations, with multiple causes and implications related to intrasexual competition and group selection (Colwell 1981, Kvarnemo and Ahnesjo 1996). In other crayfish, particularly among streamdwelling Orconectes species, apparent sex ratios can vary through the year, with 
a male-skewed ratio when females are ovigerous, and female-skewed ratios at other times of the year (DiStefano et al. 2002, Larson and Magoulick 2008), perhaps due to variations in catchability. No such evidence of seasonal sex-ratio variation with $C$. harti was observed. However, we are unsure if our data reflect real sex-bias due to differences in survival or habitat use between sexes or only apparent sex bias due to differences in activity or catchability.

\section{Reproduction}

Our results greatly expand upon what is known about the reproductive biology of $C$. harti. Hobbs (1981) reported Form I males collected in April and May. For the closely related $C$. doughertyensis, another restricted-range, obligate-burrowing species located $\approx 150 \mathrm{~km}$ from $C$. harti populations, Cooper and Skelton (2003) reported Form I males in August and small females in February. Therefore, the discovery of an ovigerous female is particularly significant. Since this animal was found in June and the greatest number of the small, free-living juveniles were collected in August, and our laboratory evidence suggests $\approx 33$-day egg-incubation time, it is likely that fertilization occurs sometime in the winter, probably October-December. However, it should be noted that Form I males were also found during the same month as the ovigerous female, and small juveniles ( $<10 \mathrm{~mm} \mathrm{CL})$ were found in November-December and August. Similar to other Cambarus species (Hobbs 1981, Loughman 2010, Taylor and Schuster 2004), there is obviously some variation in the timing of the reproductive activities. Juveniles were often associated with the burrow of a female, presumably the mother. Tolerance of juveniles by females has been observed in other burrowing Cambarus species (Loughman 2010). However, adult $C$. harti appear to ultimately segregate into individual burrows, as no burrows were encountered with multiple adults present. Also, juveniles at some point construct their own burrows as evidenced by several small-diameter openings near adult burrows. Whether these are the beginning of unique burrow complexes or merely branches from the burrow of the mother is unknown. Juvenile and adult burrows are often found in very close (many times intertangling) proximity to one another.

\section{Brooding activity}

Laboratory observations from the communal burrowing system support many of the field observations. In the $\mathrm{ABCs}$, communal burrows containing multiple adults at some point were consistently observed. This pattern was not likely due to space limitation since two chambers ( $\mathrm{B}$ and $\mathrm{C}$ ) were available but never used. This observation could be an artifact of the crayfish being held under artificial conditions and therefore not representative of natural populations. However, it is also possible that new burrows are initiated by multiple crayfish following a disturbance or dispersal and ultimately become solitary burrows as one crayfish remains while the others vacate. Individual opportunism may also play a role in that some crayfish may simply take the first available cover (e.g., an occupied burrow) temporarily to minimize vulnerability associated with being exposed. Thus, solitary burrows become more prevalent over time in established colonies. 
The observation of communal burrows in the early stages of formation deserves further attention.

As observed in the field, the single female in the laboratory that became gravid in early summer shared her maternal burrow with the resultant juveniles. Vigorous fanning activity of the eggs was not observed until the week of hatching. Interestingly, it appeared as if the left side of the egg mass was smothered by fungal filaments and sediment, while the right side contained easily visible attached juveniles. Fungal infection was not a phenomenon confined to the burrows. The gravid female collected from the field was lab-cultured in water in a flow-through tank and developed a fungal infection within several weeks, with no eggs completing development (J. Stoeckel and B.S. Helms, unpubl. data). Additional studies examining the factors contributing to fungal infections and hatching success of primary burrowers are warranted.

\section{Burrowing activity}

Although we found crayfish, particularly juveniles, throughout the year, general activity appeared to increase in the late spring and summer months. Increases in activity were significantly related to short-term decreases in groundwater level, but not to air or water temperatures. Although this finding is similar to early observations of $C$. diogenes (Tarr 1884), this relationship is counter to other more recent observations of burrowing crayfish activity, where a trend of higher activity during wet or flooded periods has been observed (Acosta and Perry 2001, Welch et al. 2008); however, variations in methodologies could account for some incongruences. Although activity surveys occurred during relatively wet periods over the study (summer 2010 and early winter 2011), the observed response may reflect increased crayfish burrowing as they track receding groundwater or clear out disturbed materials obstructing tunnels within burrows. As such, decreases in groundwater levels may be a more proximate environmental cue for these crayfish than precipitation events, though they are related.

Burrow- and chimney-construction trials revealed a similar burrowing approach as seen in other Cambarus species (Grow 1981, Grow and Merchant 1980). Burrows of $C$. harti appeared to begin as a tunnel to the groundwater, with the subsequent evolution of a large underwater chamber with several passageways and multiple surface openings, some marked by chimneys. Interestingly, chimney construction for this crayfish appears to be deliberate in that mud is formed into pellets and precisely placed, a behavior observed in other burrowing species and possibly used for species recognition (Punzalen et al. 2001, Trepanier and Dunham 1999) or regulation of airflow in the burrow (Hobbs 1981). Whatever the purpose of the chimney, it appears that the average pellet diameter of a given chimney can be used as a potential surrogate for determining the size of the individual that constructed the burrow. This correlation has important implications for estimating population structure given the cryptic nature of this species, the destructive nature needed to sample it adequately, and the fragility of its habitat. 
Perhaps not surprisingly, $C$. harti showed an affinity for excavating in typelocality soil, with the greatest separation between soil treatments occurring below the groundwater line. The below-water portion of the burrow is possibly where these crayfish are in most-direct contact with their physicochemical environment (immersion in dissolved solids, low oxygen levels, etc.) and thus where habitat preferences based on physicochemical conditions would likely manifest. A priority hierarchy may have also been observed, where simply getting below the surface is a stronger instinct than any soil-type affinities; yet once secure below the surface, crayfish seek out a preferred soil type. Whether this association with type-locality soil is a heritable preference or merely conditioning is unclear, as we used wildcaught adults removed from their native burrows. Nevertheless, these results are congruent with the habitat associated with the few known localities of this species, which is a highly organic, acidic soil associated with forested headwater springs and seeps. Like other burrowing crayfish species (e.g., Cambarus dubius Faxon [Upland Burrowing Crayfish]; Loughman 2010), C. harti appears to be a habitat specialist, and this specialization extends from its landscape distribution to its proximate habitat selection choices. However, the observation that these crayfish would burrow somewhat in a common clay-dominated soil is also valuable conservation information. Since these crayfish have such a narrow distribution within a unique habitat susceptible to human disturbance, their capacity for prolonged survival in altered conditions is encouraging. Having a broader habitat tolerance could mean that $C$. harti may exist in habitat areas that have yet to be discovered, may tolerate disturbance to their habitat, or could possibly be relocated to new marginal habitats. It should be made clear however that burrowing does not necessarily equate to survival. Soil type may influence growth, carapace formation, foraging, and competition with other species, and perhaps the ability to grow in the surprising low $\mathrm{pH}$ of their native soil releases $C$. harti from pressures they would face in other soils. Also, although strong significance in several aspects of burrowing behavior were found, caution should be used in interpretation of these burrowing trial results as a small sample size was used.

Loss of crayfish species is a growing concern throughout the US, with approximately $33 \%$ of species described being "imperiled" (Taylor et al. 2007, Wilcove and Master 2005). However, not all organisms (imperiled or otherwise) have similar influences on their respective environments to warrant an onslaught of highly coveted conservation efforts (Paine 1969, Simberloff 1998). Yet until a species' relative ecological role can be reasonably ascertained, a conservative approach is to protect (if possible), study, and then manage accordingly. This study represents an early step in quantifying basic life-history aspects of $C$. harti to determine if additional protection (e.g., federal listing as endangered) is warranted. Further studies identifying the ecological role, distribution, and population size, as well as assessments of genetic variability are needed for an increased understanding of this crayfish and possible refinement of associated conservation efforts. 


\section{Acknowledgments}

Funding was provided by USFWS Warm Springs National Fish Hatchery, Georgia Department of Natural Resources, Columbus State University, and the National Science Foundation (DEB 0949624). Sacrificed experimental animals were deposited in the Auburn University Museum of Natural History. We thank Chris Skelton, Christian Cruzen, Catlin Ames, Ian Palmer, Michael Hart, and Ray Henry for sharing their research ideas and time in the field and/or lab. Use of trade, product, or firm names is for descriptive purposes only and does not imply endorsement by any of the authors or their affiliated institutions. This paper is Contribution No. 683 of the Auburn University Museum of Natural History.

\section{Literature Cited}

Acosta, C.A., and S. Perry. 2001. Impact of hydropattern disturbance on crayfish population dynamics in the seasonal wetlands of Everglades National Park, USA. Aquatic Conservation 11:45-57.

Berrill, M., and B. Chenoweth. 1982. The burrowing ability of nonburrowing crayfish. American Midland Naturalist 108:199-201.

Colwell, R.K. 1981. Group selection is implicated in the evolution of female-biased sex ratios. Nature 290:401-404.

Cooper, J.E., and C.E. Skelton. 2003. A new burrowing crayfish of the genus Cambarus Erichson, 1846 (Decapoda: Cambaridae) from the lower Flint River basin in the Dougherty Plain of Georgia, with notes on C. (D.) hart Hobbs, 1981. Proceedings of the Biological Society of Washington 116:827-838.

DiStefano, R.J., R.J. Neves, L.A. Helfrich, and M.C. Lewis. 1991. Response of the crayfish Cambarus bartonii bartonii to acid exposure in southern Appalachian streams. Canadian Journal of Zoology 89:1585-1591.

DiStefano, R.J., J. Young, and D.B. Noltie. 2002. A study of the life history of Orconectes hylas with comparisons to Oronectes peruncus and Orconectes quadruncus in Ozark streams, Missouri, USA. Freshwater Crayfish 13:439-456.

Grow, L. 1981. Burrowing behaivour in the crayfish, Cambarus diogenes diogenes Girard. Animal Behaviour 29:351-356.

Grow, L., and H. Merchant. 1980. The burrow habitat of the crayfish, Cambarus diogenes diogenes (Girard). American Midland Naturalist 103:231-237.

Guiasu, R.C. 2009. Conservation, status, and diversity of the crayfishes of the genus Cambarus Erichson, 1846 (Decapoda, Cambaridae). Crustaceana 82(6):721-742.

Hart, D.G., and C.W. Hart, Jr. 1974. The Ostracod Family Entocytheridae. Academy of Natural Sciences of Philadelphia Monograph. 238 pp.

Hasiotis, S.T. 1993. Evaluation of the burrowing behaviour of stream and pond dwelling species of Orconectes in the Front Range of Boulder, Colorado USA: Their ethological and geological implications. Freshwater Crayfish 9:399-406.

Hobbs, H.H., Jr. 1981. The crayfishes of Georgia. Smithsonian Contributions to Zoology. No. 318.549 pp.

Johnston, C.L. and C. Figiel. 1997. Microhabitat parameters and life-history characteristics of Fallicambarus gordoni Fitzpatrick, a crayfish associated with pitcher-plant bogs in southern Mississippi. Journal of Crustacean Biology 17(4):687-691.

Kvarnemo, C., and I. Ahnesjo. 1996. The dynamics of operational sex ratios and competition for mates. Trends in Ecology and Evolution 11:404-408.

Larson, E.R., and D.D. Magoulick. 2008. Comparative life history of native (Orconectes eupunctus) and introduced (Orconectes neglectus) crayfishes in the Spring River drainage of Arkansas and Missouri. American Midland Naturalist 160:323-341. 
Loughman, Z.J. 2010. Ecology of Cambarus dubius (Upland burrowing crayfish) in north-central West Virginia. 2010. Southeastern Naturalist 9:217-230.

Metro Atlanta Chamber of Commerce 2006. Atlanta MSA growth statistics 2005-2006. Available online at http://www.investatlanta.com/media/MSAGrowthStats2006.pdf.

Paine, R.T. 1969. A note on trophic complexity and community stability. American Naturalist 103:91-93.

Pintor, L.M., and D.A. Soluk. 2006. Evaluating the non-consumptive, positive effects of a predator in the persistence of an endangered species. Biological Conservation 130:584-591.

Punzalan, D., R.C. Guiasu, D. Belchior, and D.W. Dunham. 2001. Discrimination of conspecific-built chimneys from human-built ones by the burrowing crayfish, Fallicambarus fodiens (Decapoda, Cambaridae). Invertebrate Biology 120:58-66.

Richardson, A.M.M. 1983. The effects of burrows of a crayfish on the respiration of the surrounding soil. Soil Biology and Biochemistry 15:239-242.

Simberloff, D. 1998. Flagships, umbrellas, and keystones: Is single-species management passé in the landscape era? Biological Conservation 83:247-257.

Skelton, C.E. 2010. History, status, and conservation of Georgia crayfishes. Southeastern Naturalist 9:127-138.

Skelton, C., S. Cammack, and E. Van de Genachte. 2002. Surveys of rare burrowing crayfish species. Final report submitted to Georgia Natural Heritage Program, Wildlife Resources Division, Social Circle, GA.

Sokal, R.R., and F.J. Rohlf. 1995. Biometry. 3rd Edition. W.H. Freeman and Company, New York, NY.

Stoeckel, J.A., B.S. Helms, and E. Cash. 2011. Evaluation of a crayfish burrowing chamber design with simulated groundwater flow. Journal of Crustacean Biology 31:50-58.

Stone, E.L. 1993. Soil burrowing and mixing by a crayfish. Soil Science Society of America Journal 57:1096-1099.

Tarr, R.S. 1884. Habits of the burrowing crayfishes in the United States. Nature 30:127-128.

Taylor, C.A., and G.A. Schuster. 2004. The Crayfishes of Kentucky. Illinois Natural History Survey Special Publication No. 28. 219 pp.

Taylor, C.A., G.A. Schuster, J.E. Cooper, R.J. DiStefano, A.G. Eversole, P. Hamr, H.H. Hobbs III, H.W. Robison, C.E. Skelton, and R.F. Thoma. 2007. A reassessment of the conservation status of crayfishes of the United States and Canada after 10+ years of increased awareness. Fisheries 32(8):372-389.

Trepanier, T.L., and D.W. Dunham. 1999. Burrowing and chimney building by juvenile burrowing crayfish Fallicambarus fodiens (Cottle, 1863) (Decapoda, Cambaridae). Crustaceana 72:435-442.

Welch, S.M., J.L. Waldron, A.G. Eversole, and J.C. Simoes. 2008. Seasonal variation and ecological effects of Camp Shelby burrowing crayfish (Fallicambarus gordoni) burrows. American Midland Naturalist 159:378-384.

Wilcove D.S., and L.L. Master. 2005. How many endangered species are there in the United States? Frontiers in Ecology and the Environment 3:414-420. 
Copyright of Southeastern Naturalist is the property of Humboldt Field Research Institute and its content may not be copied or emailed to multiple sites or posted to a listserv without the copyright holder's express written permission. However, users may print, download, or email articles for individual use. 